\title{
General practitioners' hypertension knowledge and training needs: a survey in Xuhui district, Shanghai
}

\author{
Qian Chen, Xiangjie Zhang, Jie Gu, Tianhao Wang, Yuan Zhang and Shanzhu Zhu*
}

\begin{abstract}
Background: Hypertension prevalence is high in China, while patients' levels of hypertension awareness, treatment and control are low. General practitioners' knowledge and training relating to hypertension prevention may be an important related factor. We aimed to investigate general practitioners' knowledge of hypertension prevention and potential training needs.
\end{abstract}

Methods: A questionnaire survey was conducted among all general practitioners at five community health service centers selected by convenience sampling. A total of 160 questionnaires were distributed and 147 were returned (response rate 91.9\%) The questionnaire included general information; 12 subjective questions on health promotion, education and training needs; and 19 objective questions in 5 domains (epidemiology, diagnosis, treatment, referral and community management) measuring knowledge of hypertension prevention and treatment.

Results: The major difficulties in health education practice for general practitioners were poor patient compliance (77.6\%) and lack of medical consultation time (49.0\%). The average accuracy rate of hypertension prevention knowledge was $49.2 \%$, ranging from $10.5 \%$ to $94.7 \%$. The factors associated with accuracy rate were physician's education level (medical university vs. professional school, $\beta=13.3, P=0.003$ ), and type of center (training base vs. community healthcare center, $\beta=12.3, P<0.0001)$. Most physicians $(87.8 \%)$ reported being willing to attend training courses regularly and the preferred frequency was once every $2 \sim 3$ months (53.5\%). The preferred course was medical treatment of hypertension (82.3\%) and the most favored training approach was expert lectures (80.3\%).

Conclusions: The knowledge level of hypertension prevention is low among general practitioners in urban settings. Physicians working in community clinics where they participate in a series of teaching, assessing and evaluating systems for hypertension prevention perform better than those in general healthcare centers who lack specific training. Continuing hypertension education is urgently needed to ensure that physicians in general practice are aware of and adhere to the national hypertension prevention guidelines.

Keywords: Awareness, General practitioner, Hypertension, Prevalence, Treatment

\section{Background}

Hypertension is a common chronic disease worldwide and a major risk factor for cardiovascular disease. National survey data suggest that the prevalence of hypertension in the Chinese adult population has quadrupled from $5 \%$ in 1959 to nearly $19 \%$ in 2002 [1]. In 2002, 153 million Chinese adults were hypertensive, with overall prevalence $24 \%$, including higher prevalence in urban

\footnotetext{
* Correspondence: zhu.shanzhu@yahoo.com.cn

General Practice Department, Zhongshan Hospital, Fudan University, 180 Fenglin Road, Xuhui District, Shanghai 200032, China
}

than in rural areas in men $(23 \%$ vs. $18 \%)$ and women (18\% vs. 16\%) [2]. A report of the China Multi-Center Study of Cardiovascular Epidemiology showed that 24\% of 1000 participants from 13 different study populations between 1992 and 1998 had hypertension, with prevalence $25.4 \%$ higher in urban than in rural areas; patients' awareness rate (aware of having a history of high blood pressure) was $42.6 \%$, treatment rate (currently using antihypertensive drugs) $31.1 \%$ and control rate (blood pressure controlled under 140/90 mmHg) 6.0\% [3]. A cross-sectional study in April 2007 in rural Shandong 
Province, China, found hypertension prevalence to be high (43.8\%), while awareness (26.2\%), treatment (22.2\%) and control of hypertension (3.9\%) were unacceptably low [4]. In Guangdong province, a province in southern China, the prevalence of hypertension in this population was $20.5 \%$, which translates to a total of 9.8 million adults who suffered from hypertension [5]. In urban regions, the prevalence of awareness, treatment, and control of hypertension among the hypertensive patients were 42.8, 37.9, and $13.5 \%$, respectively, which were higher than that among patients living in rural areas [5]. The reports above clearly indicate that prevalence in China is increasing-and that public health measures are needed to enhance awareness, treatment and control of hypertension.

Low awareness of hypertension prevention among Chinese physicians may be an important factor relating to increasing prevalence of hypertension. In China, general practitioners provide comprehensive healthcare for people of all ages with all diseases. They function in the same way as family physicians (FPs), primary care physicians or general practitioners (GPs) in other countries. However, primary care is provided by general practitioners with different levels of education; they can either be graduates of a medical college with no postgraduate training, or they can be doctors with postgraduate training and specialization [6]. Although patients seek help from general practitioners for acute illness, patients report doubting the quality of general practitioners' care for chronic illness and have more confidence in hospital clinics, which are perceived to have more qualified physicians and more modern equipment and procedures [6]. Therefore, many patients do not seek regular care from general practitioners, which can mean delayed diagnosis for asymptomatic conditions that may include hypertension.

The first edition of the "Chinese Hypertension Prevention Guide" was officially released in December 2009 [7]. It was developed jointly by the Disease Control and Prevention Bureau of the Ministry of Health, National Center for Cardiovascular Disease and the Chinese Hypertension Alliance as China's first authoritative practical hypertension prevention and treatment guide. It establishes adults' target blood pressure as SBP/DPB $<140 / 90 \mathrm{mmHg}$ in uncomplicated hypertension; < 150/90 $\mathrm{mmHg}$ for adults $>65$ years; and $<130 / 80 \mathrm{mmHg}$ for those with diabetes, coronary heart disease or renal disease. It also advises on antihypertensive drug use and emphasizes lifestyle modification such as sodium restriction, smling cessation, weight loss, reduced alcohol consumption and increased dietary potassium and physical activity as prevention and control measures. As such, the Chinese guide compares favorably to other national and international hypertension guidelines followed by general practitioners in other countries. Flynn and Flavin (2012) report that clinical guidelines for hypertension and ambulatory blood pressure in Ireland emphasize ambulatory blood pressure monitoring to improve blood pressure control in patients receiving primary care, but guideline use is limited by physician's lack of time and costs of monitoring [8]. Guidelines are widely applied in Sweden but general practitioners report accepting higher blood pressure levels than clinical guidelines advise are appropriate [9]. In the United States, guidelines are provided through continuing medical education and are shown to influence provider practice patterns and patient outcomes, serving as a costeffective strategy for prevention [10]. The 2009 Canadian Hypertension Education Program published its comprehensive recommendations for hypertension prevention and management, which included specific lifestyle modifications to restrict dietary sodium, perform aerobic exercises, maintain healthy body weight and waist circumference; detailed dietary recommendations, alcohol limitations and stress management techniques were also included as well as recommended pharmacologic agents [11]. The National Clinical Guideline Centre in the UK updated its hypertension guidelines in 2011; it comprises evidence-based advice on the care and treatment of adults with primary hypertension, including new, updated diagnosis, antihypertensive drug treatment and monitoring [12]. Most guidelines are updated annually.

The Chinese Hypertension Prevention Guide is directed to the general population (urban communities and rural health service organizations) and is designed to serve as the standard teaching guide for training primary care physicians. However, goals to increase general practitioners' awareness of the Guide, to carry out hypertension education, prevention and control in the communities and to improve hypertension awareness, treatment and control rates in hypertensive patients remain difficult tasks to accomplish nationwide. As a preliminary approach, this study aimed to investigate general practitioners' knowledge of hypertension, understanding and use of the national hypertension prevention and control guidelines, and potential training needs. Results may provide a basis for developing a hypertension training program targeted at community physicians.

\section{Methods}

\section{Subjects}

Five community health service centers in Xuhui District, Shanghai, were selected by convenience sampling based on their accessible urban setting; geographic location of the centers were considered and included one suburban area, two urban areas (not downtown) and two downtown areas to represent the general metropolitan area, which has a similar health network to other regions of China. All general practitioners in the centers were invited to participate in this study. A questionnaire survey was conducted among general practitioners at those 
centers from March 2011 to June 2011. A total of 160 questionnaires were distributed and 147 were returned (response rate $91.9 \%$ ).

\section{Definitions}

\section{General practitioner}

General practitioners in China are similar to family physicians (FPs) or general practitioners (GPs) in other countries and provide comprehensive healthcare for people of all ages, sexes, diseases and parts of the body.

\section{Physicians' titles and medical education levels}

In China, physicians include junior, attending, and senior physicians, corresponding to resident, attending physician and chief physician or deputy chief physician in other countries. Physicians' medical education levels vary from: (a) graduates of a 5-year regular medical university ("bachelors") equal to having a Bachelor of Medicine degree without clinical internship or research work; (b) graduate students with Master of Medicine or Doctor of Medicine degrees who study and perform clinical and research work for 3 to 6 years; and (c) graduates of professional school (equal to senior high school level) and medical college (3-year training in medicine after high school), a category that is being reduced.

\section{Healthcare network and work stations}

The network includes small community clinics set up as work stations by community health service centers providing public health services and patient education in residential communities. The clinics' main function is to facilitate management and follow-up of residents' chronic diseases (e.g., hypertension, diabetes mellitus), including measuring blood pressure, monitoring blood glucose, dispensing medicine and performing injections or intravenous infusion. Each site has 4 to 5 health service personnel (e.g., attending physician, 1 to 2 residents and 1 to 2 nurses) as well as out-patient clinics and wards. Community health service centers also conduct community workshop to provide academic exchange between community general practitioners and health education for community residents and patients with chronic diseases.

\section{Scope of medical services}

The five community health centers included in this study had similar functional characteristics but affiliated medical facilities in the suburbs and urban/downtown areas had differences in the scope of clinical diagnosis and treatment, as follows: (1) Full medical service: Suburban community healthcare centers have fewer surrounding secondary and tertiary hospitals/medical center to share medical services and therefore provide full medical service with a greater workload, including more patients and more types of diagnosis and treatment. (2) Basic healthcare: Downtown community healthcare centers provide basic medical services with a smaller workload, including fewer patients, fewer types of diagnosis and treatment. Urban community healthcare centers provide medical services between basic and full service.

\section{Instrument}

A questionnaire survey was conducted to investigate the hypertension knowledge and training needs of community general practitioners. The questionnaire comprised three sections (refer to Additional file 1: Appendix A for full questionnaire): (A) General information, which included physicians' baseline characteristics; health promotion, education and training needs; and knowledge of hypertension prevention and treatment; (B) Health Education and Training Needs, which included hypertension promotion, education of community general practitioners and physicians' hypertension-related training needs. It originally included 12 subjective questions presented as true/false and multiple choice questions but two items were deleted due to the low in CVI; and (C) Knowledge of hypertension prevention and control, which included 5 domains with 19 items derived from the China Hypertension Prevention Guide [7]. Domains were epidemiology with 1 item, diagnosis with 6 items, treatment with 9 items, two-way referral with 2 items and community management with 1 item. Content validity of the questionnaire was calculated as previously described by Rubio et al. [13]. Content validity was evaluated by six experts, including one professor and five senior physicians with expertise in general practice. Content validity indices (CVI) of Section B and Section C were 0.967 and 0.974, respectively.

\section{Data collection}

The questionnaires were distributed and interpreted by survey administrators. Participants were asked to complete the self-reported questionnaire without discussing with others. The completed questionnaires were collected personally by survey administrators along with signed informed consent to participate. The survey administratos were faculty of community health service centers who had received a short training course about the study purpose, questionnaire content and how to answer the questionnaire. Researchers standardized the procedure to distribute and recover the questionnaire. The authenticity and validity of the returned questionnaires were verified by researchers in research team (i.e., all questions answered by the respondent) before performing data processing and statistical analyses.

\section{Statistical analysis}

Continuous variables were summarized by mean \pm SD and categorical variables were expressed by frequencies and 
percentages. Differences in the distribution of physicians' demographic characteristics among the five participating community healthcare centers were detected by Chisquare test or Fisher's exact test, as appropriate. The accuracy rate of hypertension-related knowledge was calculated as number of correctly answered items divided by total number of items for each physician. For example, if a physician correctly answered 12 items among a total of 19 items, his accuracy rate of hypertension-related knowledge would be $12 / 19=63.2 \%$. To investigate factors associated with the accuracy rate of hypertension-related knowledge, the generalized estimating equation (GEE) model was applied to accommodate the correlated data of physicians clustered within the same healthcare center. The accuracy rate served as a continuous dependent variable, and demographic characteristics of physicians as well as characteristics of community healthcare centers served as independent variables. Univariate and multivariate GEE models with identity links were used to calculate unadjusted and adjusted mean differences and standard errors (SE) of the accuracy rate, compared to the appropriate reference group. The multivariate GEE model was constructed using backward selection procedure, wherein variables that did not improve model fit at $P<0.05$ were discarded, but age of physicians was always forced into the model for adjustment. All statistical analyses were performed with SAS software version 9.2 (SAS Institute Inc., Cary, NC). A two-tailed $P<0.05$ indicated statistical significance.

\section{Results}

\section{Baseline characteristics of general practitioners}

The baseline characteristics of general practitioners are summarized in Table 1. A total of 147 physicians completed questionnaires. Mean age of subjects was $39.8 \pm$ 10.9 years (range: $25-62$ years). More female physicians (60.7\%) were included than males $(39.3 \%)$. Less than half of physicians (49.3\%) were attending physicians, followed by junior physicians (34.7\%) and senior physicians (16.0\%). Most physicians (41.3\%) worked at community health stations. In terms of education level, a majority of physicians (78.2\%) graduated from medical university. Among the 5 community healthcare centers, significant differences were found in distributions of age $(P=0.018)$, title $(P=0.003)$, working position $(P<0.0001)$ and number of years worked $(P=0.001)$.

\section{Health education for hypertension practice among general physicians}

Almost all physicians (99.3\%) believed that changing unhealthy lifestyles will help control blood pressure, and all general practitioners (100\%) intended to practice health education for hypertensive patients during their clinic work (Table 2). Physicians encountered 4 main difficulties in health education practice, including poor patient compliance (77.6\%), lack of medical consultation time (49.0\%), lack of related educational knowledge (25.9\%), and lack of technique of behavioral medicine (e.g. communication behaviors between clinician and patient within the field) (18.4\%). Most physicians (81.0\%) believed that health education would change lifestyle of hypertensive patients to some extent, and approximately 7 in 10 physicians $(71.4 \%)$ reported spending one third to one quarter $(1 / 3 \sim 1 / 4)$ of their practice time in medication consultation with hypertensive patients. Questions from the questionnaire are shown in Table 2; the entire questionnaire can be viewed in Additional file 1: Appendix A.

\section{General practitioners' demand for hypertension prevention training}

A majority of physicians (92.5\%) had previously attended training courses on knowledge of hypertension prevention, and most physicians (87.8\%) reported being willing to attend training courses regularly (Table 2). Among physicians willing to attend regular training $(n=129)$, the preferred frequency of training courses was once every $2 \sim 3$ months (53.5\%), followed by once every month (36.4\%). Regarding topics covered in the training course, most physicians would like to learn about medical treatment of hypertension ( $82.3 \%)$, followed by educating the hypertensive patients $(66.0 \%)$ and management of hypertensive patients in the community $(57.1 \%)$. Expert lectures (80.3\%) and case study (61.9\%) were the two most favored training approaches.

\section{Hypertension prevention knowledge among general physicians}

Hypertension prevention knowledge included 5 domains with 19 items derived from the Chinese Hypertension Prevention Guide [7]. Domains were epidemiology with 1 item, diagnosis with 6 items, treatment with 9 items, two-way referral with 2 items and community management with 1 item. Accuracy rates for the five domains were $44.2 \%, 46.3 \%, 54.4 \%, 50.7 \%$, and $21.8 \%$, respectively (Table 3). Among 147 physicians, the average accuracy rate of all 19 items was $49.2 \%$, ranging from $10.5 \%$ (correctly answered 2 of 19 items, 2 physicians) to $94.7 \%$ (correctly answered 18 of 19 items, 5 physicians). The responses of general physicians to each item in this category are shown in Appendix B (Additional file 2: Table S1).

When general physicians were asked the question about current prevalence of hypertension in China, only $44.2 \%$ (65/147) answered correctly. Regarding diagnosis, 44.2\% $(65 / 147)$ of general physicians mistakenly chose the item "For patients without the use of any antihypertensive drugs, hypertension can be diagnosed if two measurements on different days show systolic blood pressure $>140 \mathrm{mmHg}$ and/or diastolic blood pressure $>90 \mathrm{mmHg}$." For blood 
Table 1 Baseline characteristics of general practitioners in different community healthcare centers

\begin{tabular}{|c|c|c|c|c|c|c|c|}
\hline \multirow[t]{3}{*}{ Characteristics } & \multirow{3}{*}{$\frac{\text { Total }}{(n=147)}$} & \multicolumn{5}{|c|}{ Community healthcare centers } & \multirow{3}{*}{ P-value } \\
\hline & & 1 & 2 & 3 & 4 & 5 & \\
\hline & & $(n=40)$ & $(n=38)$ & $(n=12)$ & $(n=32)$ & $(n=25)$ & \\
\hline Age $^{1}$ (year), n(\%) & & & & & & & $0.018^{\dagger}$ \\
\hline $21 \sim 30$ & $36(25.5)$ & $6(16.2)$ & $6(17.1)$ & $1(8.3)$ & $10(31.3)$ & $13(52.0)$ & \\
\hline $31 \sim 40$ & 53 (37.6) & $9(24.3)$ & 17 (48.6) & $7(58.3)$ & $12(37.5)$ & $8(32.0)$ & \\
\hline $41 \sim 50$ & $17(12.1)$ & $7(18.9)$ & $5(14.3)$ & $1(8.3)$ & $2(6.3)$ & $2(8.0)$ & \\
\hline$\geq 51$ & $35(24.8)$ & $15(40.5)$ & $7(20.0)$ & $3(25.0)$ & $8(25.0)$ & $2(8.0)$ & \\
\hline Gender ${ }^{2}, \mathrm{n}(\%)$ & & & & & & & $0.121^{\pi}$ \\
\hline Male & $57(39.3)$ & $12(30.0)$ & $16(44.4)$ & $3(25.0)$ & $18(56.3)$ & $8(32.0)$ & \\
\hline Female & $88(60.7)$ & $28(70.0)$ & $20(55.6)$ & $9(75.0)$ & $14(43.8)$ & $17(68.0)$ & \\
\hline Title $^{3}, \mathrm{n}(\%)$ & & & & & & & $0.003^{n}$ \\
\hline Junior physician & $50(34.7)$ & $7(18.0)$ & $9(25.0)$ & $3(25.0)$ & $14(43.8)$ & $17(68.0)$ & \\
\hline Attending physician & $71(49.3)$ & $22(56.4)$ & $20(55.6)$ & $6(50.0)$ & $16(50.0)$ & $7(28.0)$ & \\
\hline Senior physician & $23(16.0)$ & $10(25.6)$ & $7(19.4)$ & $3(25.0)$ & $2(6.3)$ & $1(4.0)$ & \\
\hline Working position ${ }^{4}, \mathrm{n}(\%)$ & & & & & & & $<.0001^{\natural}$ \\
\hline Out-patient & $47(32.9)$ & $12(31.6)$ & $15(41.7)$ & $1(8.3)$ & $19(59.4)$ & $0(0.0)$ & \\
\hline Ward & $37(25.9)$ & $14(36.8)$ & $9(25.0)$ & $7(58.3)$ & $7(21.9)$ & $0(0.0)$ & \\
\hline Community health station & $59(41.3)$ & $12(31.6)$ & $12(33.3)$ & $4(33.3)$ & $6(18.8)$ & $25(100.0)$ & \\
\hline Education level ${ }^{5}, \mathrm{n}(\%)$ & & & & & & & $0.066^{\dagger}$ \\
\hline Professional school & $9(6.3)$ & $5(13.2)$ & $1(2.8)$ & $0(0.0)$ & $2(6.3)$ & $1(4.0)$ & \\
\hline Medical College & $17(12.0)$ & $8(21.1)$ & $3(8.3)$ & $0(0.0)$ & $6(18.8)$ & $0(0.0)$ & \\
\hline Medical University & $111(78.2)$ & $23(60.5)$ & $31(86.1)$ & $10(90.9)$ & $24(75.0)$ & $23(92.0)$ & \\
\hline Graduate school & $5(3.5)$ & $2(5.3)$ & $1(2.8)$ & $1(9.1)$ & $0(0.0)$ & $1(4.0)$ & \\
\hline Years working ${ }^{6}, \mathrm{n}(\%) \mathrm{s}$ & & & & & & & $0.001^{\dagger}$ \\
\hline$\leq 10$ & 48 (33.6) & $5(12.8)$ & $9(25.0)$ & $3(25.0)$ & $14(45.2)$ & $17(68.0)$ & \\
\hline $10-19$ & 48 (33.6) & $11(28.2)$ & $17(47.2)$ & $5(41.7)$ & $10(32.3)$ & $5(20.0)$ & \\
\hline $20-29$ & 15 (10.5) & $8(20.5)$ & $3(8.3)$ & $2(16.7)$ & $1(3.2)$ & $1(4.0)$ & \\
\hline$\geq 30$ & $32(22.4)$ & $15(38.5)$ & $7(19.4)$ & $2(16.7)$ & $6(19.4)$ & $2(8.0)$ & \\
\hline
\end{tabular}

${ }^{\dagger}$ Fisher's exact test; ${ }^{\text {n }}$ Chi-square test.

${ }^{1}$ Two subjects with missing values. ${ }^{2}$ Six subjects with missing values. ${ }^{3}$ Three subjects with missing values. ${ }^{4}$ Four subjects with missing values. ${ }^{5}$ Five subjects with missing values. ${ }^{6}$ Four subjects with missing values.

pressure measuring procedure, $45.6 \%(67 / 147)$ general physicians mistakenly chose the item "The time interval between two blood pressure measurements is 1 to 2 minutes." Only 49.7\% (73/147) of general physicians correctly chose the item "The blood pressure of elderly patients (age $\geq 65$ years) with hypertension should be reduced to below 150/90 mmHg." For drug-related questions, 27.9\% (41/147) of general physicians mistakenly thought the indications of dihydropyridine calcium antagonists was left ventricular dysfunction, and 23.1\% (34/147) mistakenly thought the taboo against the use of diuretics was diabetic nephropathy. For management grade of hypertensive patients, 36.7\% (54/147) of general physicians mistakenly chose the item "For patients with target organ damage who are managed by grade, the management grade can be adjusted based on the actual situation after
1 year of management." For ambulatory blood pressure monitoring, 23.1\% (34/147) of general physicians mistakenly thought that normal ambulatory blood pressure values in China are: $24-\mathrm{h}$ average $<130 / 80 \mathrm{mmHg}$, daytime average $<140 / 90 \mathrm{mmHg}$, night time average $<120$ / $70 \mathrm{mmHg}$.

\section{Factors associated with accuracy rate of hypertension prevention knowledge}

The factors associated with accuracy rate of hypertension prevention knowledge were investigated using univariate and multivariate GEE models (Table 4). In univariate analysis, physicians with younger age, graduated from medical university, fewer years working experience and those from training base were significantly associated with higher accuracy rate. After backward selection procedure, only 
Table 2 Health education for hypertension and demand for hypertension training by general practitioners in community healthcare centers

\begin{tabular}{lc}
\hline Questions and responses & $\mathbf{n}(\%)$ \\
\hline Health Education for Hypertension & \\
1. Do you think that changing unhealthy lifestyle helps control blood \\
pressure? & $146(99.3)$ \\
$\quad$ Yes & $0(0.0)$ \\
No & $1(0.7)$ \\
Missing & \\
2. Do you intend to practice health education for patients with \\
hypertension during your regular clinic work? \\
Yes & $147(100.0)$ \\
No & $0(0.0)$
\end{tabular}

3. What is the difficulty in practicing health education to patients with hypertension? (multi-choice)

Lack of related educational knowledge

Poor compliance of patients

$114(77.6)$

Lack of technique of behavioral medicine

Lack of medical consultation time

$72(49.0)$

Other

$3(2.0)$

4. Do you think that health education will change the lifestyle of patients with hypertension?

$$
\begin{array}{lc}
\text { Yes, determinatively } & 27(18.4) \\
\text { Yes, to some extent } & 119(81.0) \\
\text { No } & 0(0.0) \\
\text { Missing } & 1(0.7)
\end{array}
$$

5. How much time did you spend on practicing health education to patients with hypertension in terms of time for medical consultation?

$\begin{array}{lc}3 / 4 \text { or more } & 5(3.4) \\ 1 / 2 & 31(21.1) \\ 1 / 3 & 46(31.3) \\ 1 / 4 & 59(40.1) \\ \text { Less or none } & 6(4.1)\end{array}$

Demands for hypertension education and training

6. Did you ever attend any training course on hypertension prevention?

$\begin{array}{lc}\text { Yes } & 136(92.5) \\ \text { No } & 6(4.1) \\ \text { Missing } & 5(3.4)\end{array}$

7. Would you like to attend training courses on hypertension prevention regularly?

$$
\begin{array}{lc}
\text { Yes } & 129(87.8) \\
\text { No } & 13(8.8) \\
\text { Missing } & 5(3.4)
\end{array}
$$

\begin{tabular}{|c|c|}
\hline Diagnosis and evaluation of hypertension & $82(55.8)$ \\
\hline Medical treatment of hypertension & $121(82.3)$ \\
\hline $\begin{array}{l}\text { Education for hypertensive patients } \\
\text { (including non-medication treatment) }\end{array}$ & $97(66.0)$ \\
\hline Management of hypertensive patients in community & $84(57.1)$ \\
\hline Two-way referral of hypertensive patients & $55(37.4)$ \\
\hline Treatment for patients with complication/comorbidity & $80(54.4)$ \\
\hline Other & $6(4.1)$ \\
\hline \multicolumn{2}{|c|}{$\begin{array}{l}\text { What kind of format(s) should be used in the related training } \\
\text { urse? (multi-choice) }\end{array}$} \\
\hline Expert lectures & $118(80.3)$ \\
\hline On-site guidance & $45(30.6)$ \\
\hline Case study & $91(61.9)$ \\
\hline Community workshop & $68(46.3)$ \\
\hline Others & $1(0.7)$ \\
\hline
\end{tabular}

8. What is the most appropriate frequency of related training course? $†$

$\begin{array}{lc}\text { Weekly } & 2(1.6) \\ \text { Bi-weekly } & 9(7.0) \\ \text { Monthly } & 47(36.4) \\ \text { Every } 2 \sim 3 \text { months } & 69(53.5) \\ \text { Don't need training course } & 2(1.6)\end{array}$

Table 2 Health education for hypertension and demand for hypertension training by general practitioners in community healthcare centers (Continued)

9. What topics should be covered in the related training course? (multi-choice)

physician's age, education level, and type of center were included in the final multivariate model. After controlling for other factors in the multivariate model, physician's age was no longer associated with accuracy rate, but education level (medical university vs. professional school, adjusted mean difference: $\beta=13.3, P=0.003$ ) and type of training center (training base vs. community healthcare center, adjusted mean difference: $\beta=12.3, P<0.0001$ ) were still significant factors associated with accuracy rate.

\section{Discussion}

This study investigated general practitioners' needs for continuing education and knowledge of hypertension prevention, which are closely associated with their understanding and use of the national hypertension prevention and control guidelines. For the questions regarding hypertension prevention knowledge, the average accuracy rate of all 19 items was $49.2 \%$, ranging from $10.5 \%$ to $94.7 \%$, suggesting that the knowledge level of general practitioners in Xuhui District, Shanghai was low. Physicians with better understanding of hypertension (i.e., higher accuracy in questionnaire answers) were more likely to be younger, with at least an undergraduate education level (i.e., having a bachelor or higher in medical degree vs. professional school education), fewer years of working experience (indicating more recent education and training) and working in a training-base. Regarding training needs, most general practitioners reported being willing to attend training courses regularly. Their preferred frequency of training courses was once every $2 \sim 3$ months, and the most preferred course was "medical treatment of 
Table 3 Accuracy rate in different domains of questionnaire for knowledge of hypertension

\begin{tabular}{cccc}
\hline Domain of items & No. of items & No. of subjects & Accuracy ratet (\%) \\
\hline Epidemiology & 1 & 147 & 44.2 \\
Diagnosis & 6 & 147 & 46.3 \\
Treatment & 9 & 147 & 54.4 \\
Two-way referral & 2 & 147 & 50.7 \\
Community Management & 1 & 147 & 21.8 \\
Total & 19 & 147 & 49.2 \\
\hline
\end{tabular}

† Average of 147 physicians.

hypertension" followed by "education for hypertensive patients (including non-pharmacologic lifestyle treatment). The most favored training approaches were expert lectures and case study. These findings indicate that physicians are eager to receive more training on addressing hypertension prevention in their communities. The increasing prevalence of hypertension and the related high risk for cardiovascular disease is a growing public health problem. Based on the quantity and structure of the Chinese population in 2010, about 200 million patients are projected to have hypertension in China, or about 2 hypertensive patients in every 10 adults [2]. Causes of the high prevalence of hypertension may be attributed to various factors, including socio-demographic factors such as older age, lower educational levels, lower income and living alone [14]. The public's lack of awareness of the presence of hypertension and lack of compliance with treatment after diagnosis are also implicated [15]. Genetic causes have been indicated as well, including the $\alpha$ adducin Gly460Trp gene polymorphism, which is linked to essential hypertension susceptibility, especially in Han Chinese [16]. To address the high prevalence of hypertension, the Chinese government has officially released a "Chinese Hypertension Prevention Guide," which is the first authoritative practical hypertension prevention and treatment guide available to Chinese practitioners and the public [7]. The guide is directed to urban communities and rural health service organizations to serve as the standard teaching guide for training primary care physicians. However, the knowledge level of general practitioners in Xuhui District, Shanghai as evidenced in the present study, is relatively low, suggesting that a considerable percentage of general practitioners do not carefully read and adhere to the published guidelines.

Barriers to adherence to national guidelines in China were suggested by results of this study. General practitioners reported four main obstacles in their practice: poor patient compliance, not enough time for medical consultation, lack of their own knowledge related to hypertension and lack of technique in behavioral medicine. Although most physicians thought that health education could influence lifestyle changes in hypertensive patients to some extent, 7 in 10 physicians reported spending only one third to one quarter of their practice time in medication consultation to educate patients about lifestyle changes that may help to reduce blood pressure and benefit their health status. Similar barriers to adherence to national and international hypertension guidelines are reported by general practitioners in other countries. The main obstacles to guideline use in Ireland as support for ambulatory blood pressure monitoring is physicians' time and the costs related to monitoring, as well as a lack of remuneration [8]. In Sweden, general practitioners report accepting higher blood pressure levels than clinical guidelines advise are appropriate [9]. Physicians included in that study reported that the advanced age of older adult hypertensive patients was a barrier to effective pharmacologic management of hypertension and that benefits of pharmacologic treatment are not obvious. About half of the physicians used risk assessment tools and nine out of ten informed their patients about the target levels for blood pressure. In Saudi Arabia, low rates for control of hypertension prompted an evaluation of primary care physicians' adherence to clinical practice guidelines [17]. In that study, only $5 \%$ of physicians measured blood pressure with patients sitting and standing, correct diagnoses of systolic and diastolic blood pressure was inconsistent among physicians, clinical examination items were not completed by all physicians, recommended diagnostic laboratory tests were missed (e.g., serum creatinine, lipid profile) and first-line anti-hypertensive agents (thiazide diuretics) were only prescribed by less than one-fifth of all participating physicians [17]. In Australia, a survey of general practice supervisors and registrars showed that hypertension was the most common problem seen by general practitioners but remained undertreated; reasons for undertreatment included lack of clarity and consistency in evidence-based guidelines, especially regarding first line treatment [18]. However, nearly $75 \%$ to $80 \%$ of untreated hypertensive adults in an Australian hypertensive medication survey had their blood pressure measured within 12 months preceding the survey $[18,19]$. In Croatia, the majority of physicians said that they support using guidelines for evaluating cardiovascular risk, but only half of physicians used them and their knowledge of specific guidelines was unsatisfactory [20]. In that study, despite 
Table 4 Univariate and multivariate factors associated with accuracy rate in knowledge of hypertension using GEE models

\begin{tabular}{|c|c|c|c|c|c|c|}
\hline & $\mathbf{n}$ & Accuracy rate (\%) & $\underline{\text { Univariate }}$ & P-value & Multivariate $^{\dagger}$ & P-value \\
\hline & & mean \pm SD & $\beta^{\ddagger}(\mathrm{SE})$ & & $\beta^{\text {ๆ }}(\mathrm{SE})$ & \\
\hline Characteristics of physician & & & & & & \\
\hline Age $^{1}$ (year) & & & & & & \\
\hline $21 \sim 30$ & 36 & $55.1 \pm 17.5$ & reference & - & reference & - \\
\hline $31 \sim 40$ & 53 & $54.1 \pm 21.3$ & $-1.0(4.7)$ & 0.832 & $1.7(4.1)$ & 0.686 \\
\hline $41 \sim 50$ & 17 & $41.8 \pm 23.1$ & $-13.3(5.4)$ & 0.013 & $-7.9(7.1)$ & 0.263 \\
\hline$\geq 51$ & 35 & $42.0 \pm 24.1$ & $-13.2(6.3)$ & 0.036 & $1.0(5.6)$ & 0.859 \\
\hline Gender $^{2}$ & & & & & & \\
\hline Male & 57 & $46.9 \pm 20.6$ & $-4.2(5.3)$ & 0.424 & & \\
\hline Female & 88 & $51.1 \pm 23.1$ & reference & - & & \\
\hline Title $^{3}$ & & & & & & \\
\hline Junior physician & 50 & $51.6 \pm 19.4$ & reference & - & & \\
\hline Attending physician & 71 & $49.0 \pm 23.4$ & $-2.6(4.5)$ & 0.562 & & \\
\hline Senior physician & 23 & $47.6 \pm 24.0$ & $-4.0(10.8)$ & 0.712 & & \\
\hline Working position ${ }^{4}$ & & & & & & \\
\hline Out-patient & 47 & $46.6 \pm 25.4$ & reference & - & & \\
\hline Ward & 37 & $49.8 \pm 20.8$ & $3.2(13.8)$ & 0.817 & & \\
\hline Community health site & 59 & $52.5 \pm 19.9$ & $6.0(8.3)$ & 0.472 & & \\
\hline Education level ${ }^{5}$ & & & & & & \\
\hline Professional school & 9 & $40.4 \pm 18.2$ & reference & - & reference & - \\
\hline Medical college & 17 & $35.0 \pm 25.7$ & $-5.4(8.8)$ & 0.543 & $-2.4(8.1)$ & 0.769 \\
\hline Medical university & 111 & $53.4 \pm 20.9$ & $13.0(6.1)$ & 0.033 & $13.3(4.5)$ & 0.003 \\
\hline Graduate school & 5 & $41.1 \pm 17.6$ & $0.7(9.5)$ & 0.941 & $4.5(11.1)$ & 0.684 \\
\hline Years working ${ }^{6}$ & & & & & & \\
\hline$<10$ & 48 & $54.7 \pm 19.0$ & reference & - & & \\
\hline $10 \leqq \sim<20$ & 48 & $53.6 \pm 20.6$ & $-1.1(2.7)$ & 0.684 & & \\
\hline $20 \leqq \sim<30$ & 15 & $45.6 \pm 20.6$ & $-9.1(9.7)$ & 0.349 & & \\
\hline$\geqq 30$ & 32 & $38.8 \pm 25.7$ & $-15.9(4.4)$ & 0.0003 & & \\
\hline Characteristics of primary care center & & & & & & \\
\hline Type of center & & & & & & \\
\hline Community Healthcare center & 72 & $45.1 \pm 19.9$ & reference & - & reference & - \\
\hline Community Teaching base & 50 & $48.3 \pm 25.1$ & $3.2(4.4)$ & 0.469 & $-1.0(3.7)$ & 0.796 \\
\hline Training base & 25 & $62.7 \pm 16.9$ & $17.6(3.0)$ & $<0.0001$ & $12.3(1.7)$ & $<0.0001$ \\
\hline Location & & & & & & \\
\hline Suburban & 32 & $49.8 \pm 12.5$ & reference & - & & \\
\hline Urban (not include downtown) & 50 & $48.3 \pm 25.1$ & $-1.5(3.3)$ & 0.645 & & \\
\hline Downtown area & 65 & $49.6 \pm 23.7$ & $-0.3(7.2)$ & 0.969 & & \\
\hline Scope of medical seervice & & & & & & \\
\hline Basic healthcare & 65 & $49.6 \pm 23.7$ & reference & - & & \\
\hline Between basic and full service & 50 & $48.3 \pm 25.1$ & $-1.2(7.9)$ & 0.875 & & \\
\hline Full medical service & 32 & $49.8 \pm 12.5$ & $0.3(7.2)$ & 0.969 & & \\
\hline
\end{tabular}

${ }^{\dagger}$ In the multivariate model, only data of 139 physicians were analyzed.

₹ Unadjusted mean difference compared to referent group.

"Adjusted mean difference compared to referent group.

${ }^{1}$ Two subjects with missing values. ${ }^{2}$ Six subjects with missing values. ${ }^{3}$ Three subjects with missing values. ${ }^{4}$ Four subjects with missing values. ${ }^{5}$ Five subjects with missing values. ${ }^{6}$ Four subjects with missing values. 
the fact that most risk factors for cardiovascular disease are modifiable and that Joint European guidelines on cardiovascular disease prevention target high-risk patients, the trends in management were described as disappointing, including that guidelines seem to be ignored [20]. Overall, physicians in the above studies seemed doubtful that guidelines actually improve patient outcomes.

In summary, responses from general practitioners in this study implied that they did not conduct hypertension consultations effectively due to lack of consultation time, which was compounded by patients' poor compliance with physicians' instructions. Although the healthcare network in China includes community health service centers that provide public health services and patient education in residential communities, with management and follow-up of residents' chronic diseases (e.g., hypertension, diabetes mellitus) performed by smaller clinics, there is clearly a need for a well-organized program for hypertension monitoring and consultation so that all hypertensive patients can receive necessary attention and education by trained physicians. The need to promote the national guidelines is obvious. The question of how to promote them remains, especially given the structure of the community health centers and the mixed educational backgrounds of general practitioners working in these centers. China has tried to standardize care throughout the national healthcare network and improve care delivered by the community health centers. Our study results do show that physicians working in the training base with a series of teaching, assessing and evaluating systems and settings for hypertension prevention perform better than those that are in general healthcare centers. This makes a strong case for continuing education for general practitioners.

The new, updated Chinese Hypertension Prevention Guide [7] sets the standard for blood pressure in normal adults as $140 / 90 \mathrm{~mm} / \mathrm{Hg}$ or below, encourages modification of lifestyle factors by all adults as a preventive measure and stresses the long-term stable control of blood pressure as one of the modifiable risk factors for cardiovascular and cerebrovascular disease, which both have high morbidity and mortality in China. The guidelines could result in improving community health if they could be promoted sufficiently to increase both physician and public awareness. The status of hypertension management in China in 2002 was characterized by patients' low awareness rate (not aware of their high blood pressure) (44.7\%), low treatment rate (poor compliance with prescribed antihypertensive medication) (28.2\%) and low control rate (poor achievement of recommended blood pressure control $<140 / 90 \mathrm{~mm} \mathrm{Hg})(8.1 \%)$ [2]. Since then, a wide range of health education and promotion has been conducted through the efforts of various levels of government and medical organizations, but surveys still show a year-to-year increasing trend in hypertension [1,2], indicating modest success, if any, in improving prevention and control in the Chinese population. The new evidence-based guidelines are available and a strategy for promoting them to physicians must be designed and implemented. Education can possibly be prioritized based on general practitioners' individual levels of medical education, emphasizing training for hypertension prevention and treatment. Meanwhile, patients' knowledge and awareness are important to preventing and controlling hypertension and available media should be used to communicate prevention information to the public. A dialogue between patients and general practitioners could ultimately benefit both the health status of the patients and the general practice of community health centers.

The present study is limited because it only surveyed general practitioners in one district of one city in China. Results may not represent the state of general practice throughout the country or in different types of institutions in the national healthcare network. Also, although we evaluated general practitioners' interest in receiving certain types of education and training to address hypertension in their communities, specific areas of weakness in their knowledge of hypertension were not evaluated in depth. In addition, our survey instrument was selfreported and general practitioners' hypertension-related skills and knowledge should ideally be measured quantitatively with an instrument designed and validated for that purpose.

\section{Conclusion}

In conclusion, the knowledge level of community general practitioners in Xuhui District, Shanghai, on understanding, preventing and managing hypertension in their communities is limited and their awareness of practice guidelines for hypertension is low. Physicians working in training bases, where they participate in a series of teaching, assessing and evaluating systems for hypertension prevention, had higher accuracy rate in hypettension knowledge than those in general community clinics where they lack specific training. Continuing education is urgently needed to ensure that physicians in general practice are aware of and adhere to hypertension prevention and treatment strategies presented in the Chinese Hypertension Prevention Guide. Increasing general practitioners' awareness and understanding of hypertension prevention and treatment is necessary to reduce the prevalence of hypertension in China. Further study is needed with a larger sample representing broader geographic distribution. Investigation of existing hypertension awareness programs, monitoring system and their level of success in 
terms of outcomes and control of hypertension also may be of value.

\section{Additional files}

Additional file 1: Appendix A. Questionnaire: Hypertension Knowledge and training needs for Community General Practitioners.

Additional file 2: Table S1. Responses for knowledge of hypertension.

\section{Competing interests}

The authors declare that they have no competing interests.

\section{Authors' contributions}

We declare that all the listed authors have participated actively in the study and all meet the requirements of the authorship. Dr. (QC, SZ) designed the study and wrote the protocol, Dr. (QC, XZ, JG) performed research/study, Dr. (TW, YZ) managed the literature searches and analyses, Dr. (QC, JG) undertook the statistical analysis, Dr. (QC, XZ) wrote the first draft of the manuscript. All authors read and approved the final manuscript.

\section{Authors' information}

Qian Chen and Xiangjie Zhang are co-first authors in this study.

\section{Acknowledgements}

This study was supported by a research fund from Fudan University, Shanghai China for young scientist. We thank all participants and all the staff in five community health service centers in Xuhui District, Shanghai, for their efforts that made this study possible.

Received: 18 July 2012 Accepted: 21 January 2013

Published: 28 January 2013

\section{References}

1. Wu Y, Huxley R, Li L, Anna V, Xie G, Yao C, Woodward M, Li X, Chalmers J, Gao R, Kong L, Yang X, China NNHS Steering Committee, China NNHS Working Group: Prevalence, awareness, treatment, and control of hypertension in China: data from the China National Nutrition and Health Survey 2002. Circulation 2008, 118:2679-2686.

2. Gu D, Reynolds K, Wu X, Chen J, Duan X, Muntner P, Huang G, Beynolds RF, Su S, Whelton PK, He J, Interasia Collaborative Group: Prevalence, awareness, treatment, and control of hypertension in China. Hypertension 2002, 40:920-927.

3. Wang Z, Wu Y, Zhao L, Li Y, Yang J, Zhou B: Trends in prevalence, awareness, treatment and control of hypertension in the middle-aged population of China, 1992-1998. Hypertens Res 2004, 27:703-709.

4. Li H, Meng Q, Sun X, Salter A, Briggs N, Hiller J: Prevalence, awareness, treatment, and control of hypertension in rural China: results from Shandon Province. J Hypertens 2010, 28:432-438.

5. Ma WJ, Tang JL, Zhang YH, XU YJ, Lin JY, Li JS, Lao XQ, Tam WW, Wong MC, Yu IT: Hypertension prevalence, awareness, treatment, control, and associated factors in adults in southern China. Am J Hypertens 2012, 25:590-596.

6. Mercer SW, Siu JY, Lam CLK, Lo YYC, Lam TP, Griffiths SM: A qualitative study of the views of patients with long-term conditions on family doctors in Hong Kong. BMC Fam Pract 2010, 11:1471-2296.

7. Liu LS, Wang W, Yao CH: Chinese guideline for the prevention and treatment of hypertension. Joint issue by ministry of health, bureau for disease prevention \& control, center of national cardiovascular diseases and Chinese hypertension alliance. Beijing: Ding-Xiang-Yuan Medical Forum Publishers; 2009. in Chinese.

8. Flynn E, Flavin A: General practitioner's reported use of clinical guidelines for hypertension and ambulatory blood pressure. Ir Med J 2012, 105:89-91.

9. Midlov P, Ekesbo R, Johansson L, Gerward S, Persson K, Nerbrand C, Hedblad B: Barriers to adherence to hypertension guidelines among GPs in southern Sweden: A survey. Scand J Prim Health Care 2008, 26:154-159.

10. Trogdon JG, Allaire BT, Egan BM, Lackland DT, Masters D: Training providers in hypertension guidelines: cost-effectiveness evaluation of a continuing education program in South Carolina. Am Heart J 2011, 162:786-793.

11. Khan NA, Hemmelgarn B, Herman RJ, Bell CM, Mahon JL, Leiter LA, Rabkin SW, Hill MD, Padwal R, Touyz RM, Larochelle P, Feldman RD, Schiffrin EL,
Campbell NR, Moe G, Prasad R, Arnold MO, Campbell TS, Milot A, Stone JA, Jones C, Ogilvie Rl, Hamet P, Fodor G, Carruthers G, Burns KD, Ruzicka M, DeChamplain J, Pylypchuk G, Petrella R, Boulanger JM, et al: The 2009 Canadian Hypertension Education Program recommendations for the management of hypertension: Part 2-therapy. Can J Cardiol 2009, 25:287-298.

12. National Clinical Guideline Centre (UK): Hypertension: the clinical management of primary hypertension in adults: update of clinical guidelines. London: Royal College of Physicians (UK); 2011. CG127 Hypertension: full guideline, http://guidance.nice.org.uk Accessed Dec. 17, 2012.

13. Rubio DM, Berg-Weber M, Tebb SS, Lee ES, Rauch S: Objectifying content validity: conducting a content validity study in social work research. Social Work Res 2003, 27:94-104.

14. Li WW, Stewart AL, Stotts N, Froelicher ES: Cultural factors associated with antihypertensive medication adherence in Chinese immigrants. J Cardiovasculat Nurs 2006, 21:354-362.

15. Li S, Sit W, Gong J, Wong M, Zheng Y, Wong T: Hypertension prevalence, awareness, treatment and control in the urban distric of Wuhan, China: implications for community nursing practice. J Nurs Care 2012, 1:106.

16. Li YY: A-adducin Gly-460-Trp gene mutation and essential hypertension in a Chinese population: a meta analysis including 10960 subjects. PLOS One 2012, 7:e30214.

17. Al-Gelban KS, Khan MY, Al-Khaldi YM, Mafouz AAR, Abdelmoneim I, Daffalla A, Mostafa OA, Al-Amri HS: Adherence of primary health care physicians to hypertension management guidelines in the Aseer Region of Saudi Arabia. Saudi J Kidney Dis Tranpl 2011, 22:941-948.

18. Eastman P: Antihypertensive prescribing. A survey of general practice supervisors and registrars. Aust Fam Phys 2008, 37:969-971.

19. Briganti EM, Shaw JE, Chadban SJ, Zimmet PZ, Welborn TA, McNeil JJ, Atkins RC: Untreated hypertension in Australian adults: the 1999-2000 Australian Diabetes, Obesity and Lifestyle Study (Aus Diab). Med J Aust 2003, 179:135-139.

20. Reiner Z, Sonicki Z, Tedeschi-Reiner E: Physicians' perception, knowledge and awareness of cardiovascular risk factors and adherence to prevention guidelines: The PERCRO-DOC survey. Atherosclerosis 2010, 213:598-603.

\section{doi:10.1186/1471-2296-14-16}

Cite this article as: Chen et al:: General practitioners' hypertension knowledge and training needs: a survey in Xuhui district, Shanghai. BMC Family Practice 2013 14:16.

\section{Submit your next manuscript to BioMed Central and take full advantage of:}

- Convenient online submission

- Thorough peer review

- No space constraints or color figure charges

- Immediate publication on acceptance

- Inclusion in PubMed, CAS, Scopus and Google Scholar

- Research which is freely available for redistribution 